\title{
OUTREACH AND EFFECTS OF THE ECB CORPORATE SECTOR PURCHASE PROGRAMME*
}

\author{
Jakub Jakla
}

\begin{abstract}
This paper analyses the effects of the ECB Corporate Sector Purchase Programme (CSPP) on yields of corporate sector bonds and its impact on the corporate sector's debt markets. The CSPP started as a part of an existing asset purchase programme and significantly affected corporate bond markets. Any research undertaken in this area of the ECB's respective actions is fairly limited due to the restrained access to data and its OTC nature. This paper analyses CSPP effects by using two distinct methods - a detailed regressioncontrolled event study and an impulse-response analysis of constructed VAR models. This study addresses questions regarding time, size and place of effects caused by the CSPP on corporate bond markets and deals in detail with related issues and related economic theory backgrounds. A series of obtained sector, country and company-specific results gives us a picture of the non-negligible impact of the CSPP on purchased bonds and of the size and persistency of stock and flow effects of the ECB's actions.
\end{abstract}

Keywords: Quantitative easing, corporate bonds, Corporate Sector Purchase Programme JEL Classification: E52, E44, G12

\section{Introduction}

The ECB Governing Council decided in March 2016 to introduce a new part of its asset purchase programme (APP) alongside other well-established ones, such as the Public Sector Purchase Programme (PSPP), this time targeting corporate sector bonds - the Corporate Sector Purchase Programme (CSPP). It was designed as an additional measure taken in order to ease funding conditions in the non-bank corporate sector by lowering the yields of corporate bonds and thereby reducing the costs of funding. The CSPP came into force

a University of Economics, Faculty of Finance and Accounting, Prague, Czech Republic Email: xjakj14@vse.cz

* This paper is a part of IGA project F1/18/2017 "Macro-financial stability and the financial cyclein countries with a negative net investment position".

1 Secondary market purchases $85 \%$, primary market purchases $15 \%$. 
in June 2016 and by the end of 2017, the total ECB holdings were more than 130 billion EUR of securities. ${ }^{1}$ The eligible universe consists of over 1,400 issues with a face value of over 800 billion EUR of investment-grade (IG) euro-denominated bonds issued by non-bank corporations. Purchases are planned to continue at least until September 2018 at a current monthly pace of 30 billion EUR. As for impact on other than targeted markets, we can mainly think of ineligible corporate bonds consisting of another more than 600 billion EUR.

The questions answered in this paper are: How much were bond markets affected, both eligible and ineligible? In what industry and country was the effect on yields the most significant? In what phase of the CSPP introduction was the effect on corporate bond yields measurable and what were the causes and consequences? Were companies from the eurozone (EZ) motivated to raise issuance and restructure company debt exposure towards bond issuance rather than bank financing? What transmission mechanism does probably stand behind it?

Due to limited accessibility of relevant data and analysis challenges, there is virtually no existing research on the CSPP going beyond a very basic analysis of the CSPP. In this study, several methods are used to investigate the CSPP in more detail and to overcome problems arising from the fact that decisions on the CSPP are made together with conventional rate decisions and the other APP programmes and are wrapped in forward guidance. Firstly, a controlled-event study (ES) was used to examine the immediate impact of CSPP announcements, its implementation and effects of preceding discussion and expectations about the programme on corporate bond yields. Secondly, a vector autoregression (VAR) model and its subsequent impulse-response functions (IRFs) were used to assess the impact of ECB activities on bond markets. And finally, an analysis of estimated ECB holdings shows yield changes in constructed synthetic corporate bond portfolios and gives us a picture about the funding costs of selected companies. All these approaches together also form a wider picture of possible stock and flow effects of the CSPP and provide us with more details on present transmission of monetary policy programmes aiming at asset prices.

\section{CSPP and Its Framework}

Eligible conditions on bond purchases in the CSPP are: non-financial companies with 6 months to 31 years to mature, denominated in euros, with investment-grade credit rating and with yield to maturity (YTM) not lower than the ECB deposit rate. The issue share limit is $70 \%$ per ISIN and the issuer limit follows a predefined benchmark. The purchases were initiated at a monthly pace of 80 billion EUR, changed to 60 billion EUR since April 2017, and the current pace of 30 billion EUR will continue until September 2018. All the figures are for the APP as a whole - mainly the PSPP and CSPP. The ECB (2017) 
informed about CSPP purchases that the monthly net purchases from June 2016 to May 2017 ranged from 4 billion EUR to below 10 billion EUR.

Monetary policy today is characterized by affecting asset prices - targeted asset price changes transfer to other assets and ultimately affect unemployment, inflation, GDP and other macroeconomic variables via a complex system of relationships. In the case of the APP, it targets sovereign and corporate sector bonds to change their price and yield. The effect of lowering the yields is achieved via several different transmission channels first of all, a signalling channel by announcements of unexpected moves of a central bank, where the reaction of asset prices is more or less instant and depends on the credibility of the given central bank. When the ECB announced in March 2016 its intention to purchase corporate bonds staring in June, the reaction on markets for these bonds was already present in the following days and weeks, yet with no real actions of the ECB on markets. In the world of New Keynesian economics and Ricardian equivalence, a signalling channel works only to disseminate how much the ECB is able to influence expectations of the average economic agent regarding the expected future path of its rates or expected effects of its asset purchases. This channel is examined, e.g., in Eggertsson and Woodford (2003) or Clouse et al. (2003).

A frequently mentioned transmission channel, with a connection to asset prices, is the portfolio-rebalancing channel, described, e.g., in D'Amico and King (2010), Hamilton and $\mathrm{Wu}$ (2011) or Gagnon et al. (2011). It works via relative changes in nominal asset prices with respect to nominal prices of other assets that are being considered as an investment alternative. Investors initiate a portfolio-rebalancing process when they see an opportunity to optimize their own portfolio to bear maximum yield given the existing risks when the current portfolio yields are affected by external factors. ECB purchases are designed to lower yields on prime corporate bonds and when they do, investors will demand lower credit premiums in the segment of less attractive alternative investment assets, mainly in other corporate bonds. Money spent by the ECB to buy bonds goes via bond sellers to other segments of the market and possibly finds its way to issuers of other, less favoured corporate bonds - the ECB also aims to lower funding costs for SMEs in the EZ.

Another possible channel of transmission, especially important on less liquid markets, is the liquidity channel, mentioned in Krishnamurthy and Vissing-Jorgensen (2011). By its presence on markets with lower liquidity, such as markets for corporate bonds, the ECB supplies liquidity and represents a possible counterparty for other investors and allows them to trade without additional costs caused by low liquidity. Liquidity premiums are reduced, and investors hold these assets more willingly.

Another type of premiums required from investors for holding a certain type of assets is term premiums, depending on the time to mature of a given asset. Investors 
are simply risk-averse on average and holding bonds with 9 years to mature is simply not equivalent to repeatedly holding 3 -year bonds with the same coupon during those 9 years. The preferred habitat model developed by Vayanos and Vila (2009) and the imperfect asset substitution problem (market segmentation) analysed by Andrés et al. (2004) represent a fraction of various papers studying this type of premiums. During CSPP implementation, the ECB bought a part of corporate bonds with longer maturities and could have lowered the term premiums on corporate bond markets. All three types of premiums mentioned above are analysed in Section 5.

\section{Event Study Analysis}

\subsection{Data and methodology}

This section employs an event study (ES) methodology to quantify the effects of CSPPrelated events (ECB's monetary policy decisions and minutes, Governing Council members' speeches and main CSPP news) on yields of corporate bonds. The ES is frequently used by central banks and monetary policy researchers to tackle the effects of monetary policy (see, e.g., Briciu and Lisi, 2015; Joyce et al., 2012; or Altavilla et al.; 2015). A tailored version of the ES is employed in this study to identify the effects of policy decisions from other economic and political events. A imilar approach is used, e.g., by the ECB (2017) for quantifying the effects of the announcements of non-standard measures in 2014-2015, at that time with no focus on corporate bonds. The ES analysis considers all important CSPP-relevant events in 2016 and 2017. As for the correct time window for assessing the effect of related events, the most common two-day time window is used for each included event; the same length is used, e.g., in Krishnamurthy and Vissing-Jorgensen (2011) or Hausken and Ncube (2013). A one-day window would possibly not capture the slow reactions of less-liquid bonds and a three-day window could easily capture other effects misleadingly. Furthermore, the ES is adjusted for movements caused by major periodic economic releases by estimating adjusting regressions.

Our set of base ES events consists only of CSPP-related and CSPP-positive events - it would be unclear how to assess all speeches of ECB members, sources and market news in a hawkish tone, with signs of QE tapering or lowering the CSPP purchases (not CSPP-positive). ${ }^{2}$ Altogether, the event set consists of the following 52 events of 5 types listed below and captured on the timeline in Figure 1:

2 Twelve other base event sets were, however, analysed to decide on the appropriateness of the chosen event set. 
(1) ECB monetary policy decisions (2 events),

(2) ECB monetary policy accounts (3 events),

(3) ECB news with major market impact (“ECB sources") (8 events),

(4) speeches of Governing Council members about the CSPP (16 events),

(5) major CSPP-related high-impact news from Bloomberg or Thomson-Reuters (23 events).

Figure 1: CSPP - Related Event Timeline

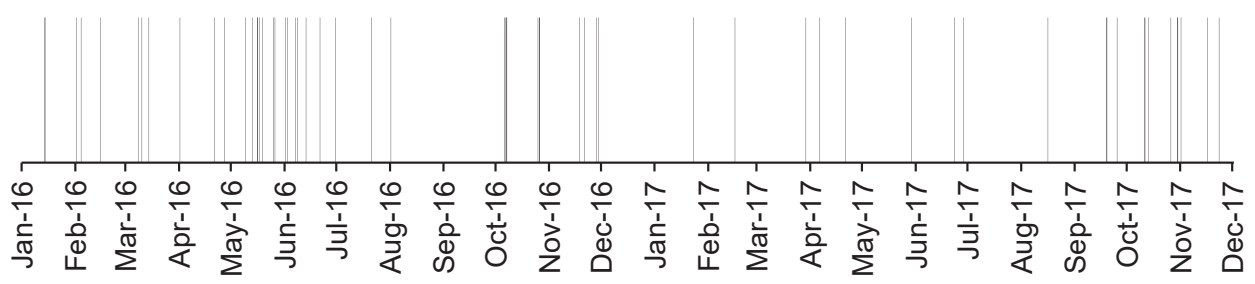

Note: each vertical line represents an event included in the event study

Source: ECB, Bloomberg, Thomson-Reuters

The first (1) and second (2) type of events mentioned above naturally include key ECB decisions regarding the CSPP from March 2016 and October 2017 and corresponding minutes plus the CSPP-promising minutes from January 2016. As for the third type (3), these are unexpected CSPP news from anonymous sources close to the ECB, which usually have the power to increase volatility on markets. The next event type (4) stands for all public speeches of Governing Council members referring in some way to the CSPP. Type (5) represents all highly influential news on the CSPP published by Bloomberg or Thomson-Reuters - an extensive search on CSPP-related news was undertaken among all news from 2016-2017 and only the major news items on the CSPP were selected. ${ }^{3}$

As for major global macroeconomic and geopolitical events in 2016-2017, there is fortunately no direct interference with the ES windows defined in this paper around the selected base events, but the effects of these political events can still be expected to affect this ES in the medium and long term by entering the other windows but cannot be easily estimated and separated from other acting factors. The following geopolitical events are taken into consideration in this paper and also reflected in the VAR analysis:

3 The selection is based on professional bond market-maker expertise. 
Brexit referendum, UK High Court decision on Article 50, US presidential election, Italy's constitutional referendum, the "sequel" to Greece's bailout debate, French presidential election, UK general election and Catalan regional election.

To fine-tune the ES findings and to adjust them for effects of macroeconomic releases, such as GDP, CPI, etc. ${ }^{4}$, this study employs nonlinear regressions on selected macroeconomic releases on intraday high-frequency data of the period 2014-2017 and estimates what part of yield change on that day was caused by macroeconomic data releases that fell in the ES time window and what part had a different cause (possibly the CSPP). This simple model estimates the impact of major periodic macroeconomic releases of the US, the UK, the EZ, Germany, France, Italy and Spain that fell into the two-day window around the ES events and quantifies their direct impact on bond markets of selected maturities in Germany, France, Italy and Spain. The regressions are based on a surprise factor derived from the actual value of the data release and the surveyed value according to Bloomberg's event surprise methodology and historical intraday movements of futures of sovereign bonds. ${ }^{5}$ The bid-to-cover ratio is used for government bond auctions instead of the surprise factor, which is not provided for auctions. Highly efficient fixed-income derivatives markets are known to absorb economic release surprises fairly quickly; therefore, a 3-minute interval was used for each particular event for each release type (e.g., CPI in Germany). The regressions then incorporate the price change between the time of release $(\mathrm{T})$ and $\mathrm{T}+3$ minutes, which is one beat, as a dependent variable and the Bloomberg-provided surprise factor (bid-to-cover ratio in the case of bond auctions) as a regressor.

The formal representation of the regressions used in the ES to adjust for the impact of economic releases is based on Bates and Watts (1988) and is written as:

$$
y_{i}=C_{i}+\theta_{i, 1} x_{i}^{\theta_{1,2}}+\varepsilon_{i},
$$

where the dependent variable $y_{i}$ is a price (yield) change of underlying bonds, $C_{i}$ is the estimated constant (intercept), $x_{i}$ is the independent variable representing a release surprise, $\theta_{i, 1}$ and $\theta_{i, 2}$ are the estimated parameters and $\varepsilon_{i}$ is the normally distributed error term. In this case $C_{i}=0$, because no surprise in an economic release, more precisely no deviation from market participants' expectations regarding an economic release, naturally causes no price change. The parameters $\theta_{i, 1}$ and $\theta_{i, 2}$ are estimated in order to constitute

4 The complete list of incorporated releases by their home countries: CPI, GDP, PMI manufacturing and employment indicators (for US, UK, GE, FR, IT, SP, EC); government bond auctions (for GE, FR, IT, SP); monetary policy rates (for US, UK); durable goods orders, ISM manufacturing and retail sales (for US).

5 Based on intraday H-F data from Eurex Exchange on Schatz, Bobl, Bund, OAT, Mid-Term OAT, Long-Term BTP and Short-Term BTP Futures. 
an unbiased model - the primary objective is to provide a better data fit with smallest possible standard errors (SE) of the estimated regression with random residuals with no pattern in the residual plot. ${ }^{6}$ The estimated regressions are of a polynomial function shape - no surprise in a release is accompanied by no reaction; bigger surprises are accompanied by a bigger reaction of a price change and this applies more or less to all release types. ${ }^{7}$ These initial assumptions given the data and their optional handling give us parameter requirements on $\theta_{i, 1}>0$ and $\theta_{i, 1}>1$. The estimated regression functions represent the relation between the dependent price (yield) change and the independent surprise factor derived from an economic release and economic estimates of market participants. Consequent adjustments for effects of macroeconomic releases are then made by simply taking the value of $y_{i}$ that belongs to given $x_{i}$ on an estimated function and adjust the ES findings in the given time window with respect to the price (yield) movement direction.

The same price adjustment could be done by a simple calculus of price changes around the given time interval for the given event; however, the presented approach represents a more rigorous way to incorporate this issue. This approach allows us to cover adjustments with a type of estimated "response function" rather than with a simple price shift caused by every single release. However, the results of the regression-estimated adjustments are fairly comparable with results otherwise calculated from a simple yield change within a three-minute interval (one beat) around the release and represent only a minor fine-tuning adjustment: e.g., an adjustment for the CPI in Germany stemming from regression estimates is around -5 b.p. for 5 -year and -3 b.p. for 10 -year government bond yield. ${ }^{8}$ The impact of economic releases on corporate non-bank CSPP-eligible bonds is expected, for the sake of simplicity, to be the same as for the model-estimated impact on sovereign bonds of a corresponding country with the same maturity.

Daily data for ES itself consist of non-bank corporate bond yields adjusted for individual rating changes of issuers in the given period ${ }^{9}$, Euro Emerging Markets Corporate

$6 \quad$ Since R-squares and p-values would not be valid for a non-linear regression.

7 Absolute values of price changes are used to estimate regressions, which is in line with praxis of estimating the relative importance and reactions of the given events, when direction of the price movement does not matter. The direction of each price change for all releases was, however, considered in following ES adjustments based on estimated regressions.

8 Estimated price movement adjustments for economic release surprises on government bonds of selected states are on average accountable approximately only for $1 \%$ of total price movement on given days (e.g., for German bonds it is 1.01\% for Schatz, 1.02\% for Bobl, $0.99 \%$ for Bund and $1.13 \%$ for Buxl).

9 The rating changes in 2016-2017 made by S\&P, Moody's and Fitch. Data of rated companies were excluded from the dataset on rating days. 
Plus effective yield sub-index (ICE1) and Euro High Yield effective yield index (ICE2). ${ }^{10}$ The dataset of ECB CSPP-eligible bond yields consists of over 1,100 specific corporate issues across the EZ and the maturity range targeted by the ECB in 2016-2017. For illustrational purposes and to see the whole picture of the EZ economy, changes in Euro-Stoxx 50, the EUR-USD spot exchange rate and the VIX index are analysed as well.

The ES results are further adjusted for overnight index swap (OIS) rate movements this approach, presented and argued in Joyce et al. (2011) gives us a better view of changes in asset prices caused by unconventional monetary policy. Joyce et al. (2011) used the spread between OIS and sovereign bond yields to separate two effects of monetary policy - the first one that captures a change in expectations about future monetary policy rates and the second one that captures possible changes in term and credit premiums. The OIS rates as such carry minimal counterparty credit and liquidity risk and fully reflect expectations about future rate paths, this fact predestines the OIS rates to be a good proxy for the change in expectations about future monetary policy rates and allows us to quantify the second component of $\mathrm{QE}$ announcements that reflects mainly changes in term and credit premiums rather than future ECB rates.

\subsection{Event study results}

The changes in prices/yields of assets around the ES events connected with the CSPP are captured in Tables 1-3. The column "Total change" stands for the total change (sum) in b.p. (for yields), in pips (for EUR-USD) and in index points (for VIX and EuroStoxx50) in 2016-2017. The column "ES change", expressed in the same scales, stands for the sum of changes in two-day windows capturing effects induced by all 52 CSPP-related events covered by this ES.

The left part of Table 1 contains average yield changes - it comes as no surprise that the longer the maturity, the bigger the effect. Change in the maturities closest to the average ECB portfolio composition (which was circa 6 years) in 5-year and in 7-year maturity is both around -40 b.p. On the short end of the curve, the 2-year yield changed by -25 b.p. and the change on the 10 -year yield was -42 b.p. The biggest yield changes are present in two event clusters in Q2 2016 and Q4 2017 (see Figure 1), which are the quarters of the key CSPP decisions. The right part of Table 1 contains the same average yield changes adjusted for OIS movements derived from Eonia changes for given maturities.

10 Both indices provided by ICE and BofA-ML. 
Table 1: AYTM change (in b.p.)

\begin{tabular}{l|c|c}
\hline Tenor (years) & Total change & ES change \\
\hline $\mathbf{1}$ & -47.9 & -18.0 \\
\hline $\mathbf{2}$ & -64.6 & -25.3 \\
\hline $\mathbf{3}$ & -60.0 & -33.3 \\
\hline $\mathbf{5}$ & -70.6 & -44.1 \\
\hline $\mathbf{7}$ & -59.3 & -39.5 \\
\hline $\mathbf{1 0}$ & -61.5 & -42.2 \\
\hline $\mathbf{2 0}$ & -80.1 & -69.2 \\
\hline
\end{tabular}

\begin{tabular}{l|c|c}
\hline Tenor (years) & Total change -OIS & ES change -OIS \\
\hline $\mathbf{1}$ & -43.8 & -24.2 \\
\hline $\mathbf{2}$ & -66.9 & -24.7 \\
\hline $\mathbf{3}$ & -65.8 & -31.3 \\
\hline $\mathbf{5}$ & -74.8 & -35.6 \\
\hline $\mathbf{7}$ & -59.2 & -26.0 \\
\hline $\mathbf{1 0}$ & -55.7 & -32.7 \\
\hline $\mathbf{2 0}$ & -69.7 & -65.1 \\
\hline
\end{tabular}

Source: own calculations

The right side of Table 1 shows that change in yields adjusted by OIS of the corresponding maturity is smaller than unadjusted, which possibly implies that policy of $\mathrm{QE}$, forward guidance and rate decisions are used closely together and in this case the implementation of QE is clearly perceived by markets as "lower rates for a longer period". The key CSPP decision in March 2016 was in fact taken together with the ECB rate change, when the deposit rate was lowered by 10 b.p. The OIS-adjusted change of average yield to maturity (AYTM) in non-bank corporate 5-year bonds, the most purchased maturity, is around -36 b.p., which would mean a success of the ECB in sending a signal strong enough to make a real difference in asset prices.

Table 2 shows the comparison of maturities and countries for Germany, France, Italy and Spain. Country-specific macroeconomic releases are dealt with using the procedure mentioned in the first part of this section and possible longer-lasting geopolitical effects on yields are tackled by inclusion of corporate-sovereign bond spread in the right part of Table 2. By comparing the yield spread changes of corporates and their benchmark country sovereign bonds of the same maturity - e.g., French corporates are compared to French government bonds, etc. Possible affection by the PSPP could be partially caused by the APP increase in March 2016 to 80 billion EUR starting in April 2016 and first real CSPP purchases starting in June 2016. Before the March 2016 decision, the PSPP stood approximately for 50 billion EUR, in April 2016 increased to almost 80 billion EUR and since June 2016 it was partially replaced by CSPP purchases around 10 billion EUR a month. No doubt that sovereign bonds had to be affected to some extent by the ECB's decision in March 2016 and the comparison of corporate bonds with its benchmark sovereign bonds is therefore very convenient and it helps us to abstract from the mentioned issues and to focus solely on CSPP-related effects. 
Table 2: AYTM change by country (in b.p.)

\begin{tabular}{|c|c|c|}
\hline $\begin{array}{l}\text { Tenor (years) / } \\
\text { Country }\end{array}$ & $\begin{array}{l}\text { Total } \\
\text { change }\end{array}$ & $\begin{array}{c}\text { ES } \\
\text { change }\end{array}$ \\
\hline $1 \mathrm{GE}$ & -31.3 & -13.5 \\
\hline $1 \mathrm{FR}$ & -57.1 & -13.5 \\
\hline 1 IT & -25.2 & -28.1 \\
\hline $1 \mathrm{SP}$ & 68.6 & -153.4 \\
\hline $2 \mathrm{GE}$ & -50.4 & -0.7 \\
\hline $2 \mathrm{FR}$ & -54.3 & -36.7 \\
\hline 2 IT & -54.3 & -31.3 \\
\hline $2 \mathrm{SP}$ & -71.5 & -15.0 \\
\hline $3 \mathrm{GE}$ & -54.0 & -2.2 \\
\hline $3 \mathrm{FR}$ & -38.5 & -34.0 \\
\hline 3 IT & -74.1 & -63.4 \\
\hline $3 \mathrm{SP}$ & -66.3 & -52.0 \\
\hline $5 \mathrm{GE}$ & -54.4 & 2.8 \\
\hline $5 \mathrm{FR}$ & -52.9 & -49.6 \\
\hline 5 IT & -82.0 & -64.6 \\
\hline $5 \mathrm{SP}$ & -62.7 & -77.2 \\
\hline $7 \mathrm{GE}$ & -63.0 & -11.9 \\
\hline $7 \mathrm{FR}$ & -62.8 & -52.6 \\
\hline 7 IT & -64.3 & -71.2 \\
\hline $7 \mathrm{SP}$ & -36.7 & -65.4 \\
\hline $10 \mathrm{GE}$ & -62.5 & -20.7 \\
\hline $10 \mathrm{FR}$ & -60.4 & -44.7 \\
\hline 10 IT & -54.7 & -88.2 \\
\hline $10 \mathrm{SP}$ & -28.8 & -107.8 \\
\hline
\end{tabular}

\begin{tabular}{|c|c|c|}
\hline $\begin{array}{l}\text { Tenor (years) / Country } \\
\text { - spread change with } \\
\text { sovereign benchmark bond }\end{array}$ & $\begin{array}{l}\text { Total } \\
\text { change }\end{array}$ & $\begin{array}{c}\text { ES } \\
\text { change }\end{array}$ \\
\hline $1 \mathrm{GE}$ & 1.3 & 7.9 \\
\hline $1 \mathrm{FR}$ & -30.1 & -21.6 \\
\hline $1 \mathrm{IT}$ & 7.8 & -19.6 \\
\hline $1 \mathrm{SP}$ & 101.0 & -184.7 \\
\hline $2 \mathrm{GE}$ & -15.2 & 17.8 \\
\hline $2 \mathrm{FR}$ & -29.2 & -21.8 \\
\hline 2 IT & -16.8 & -42.6 \\
\hline $2 \mathrm{SP}$ & -26.3 & -11.0 \\
\hline $3 \mathrm{GE}$ & -24.3 & 13.3 \\
\hline $3 \mathrm{FR}$ & -18.9 & -44.3 \\
\hline 3 IT & -51.1 & -74.4 \\
\hline 3 SP & -52.0 & -59.7 \\
\hline $5 \mathrm{GE}$ & -30.5 & 22.4 \\
\hline $5 \mathrm{FR}$ & -34.0 & -45.7 \\
\hline 5 IT & -68.7 & -31.3 \\
\hline $5 \mathrm{SP}$ & -29.6 & -40.2 \\
\hline $7 \mathrm{GE}$ & -42.2 & 13.5 \\
\hline $7 \mathrm{FR}$ & -42.2 & -43.0 \\
\hline 7 IT & -61.1 & -21.9 \\
\hline $7 \mathrm{SP}$ & 12.2 & -17.9 \\
\hline $10 \mathrm{GE}$ & -39.8 & 10.9 \\
\hline $10 \mathrm{FR}$ & -32.7 & -29.6 \\
\hline 10 IT & -66.3 & -38.5 \\
\hline $10 \mathrm{SP}$ & 5.4 & -24.6 \\
\hline
\end{tabular}

Source: own calculations

It is obvious from Table 2 on the spread with benchmark bonds that the effect on CSPPeligible bonds is partially affected by the co-movement of benchmark bonds. It is clearly the case of longer maturities and of Italy and Spain. On the other side stands Germany with a completely different pattern - German government bonds have a special position in the EZ and they are widely recognized as benchmark bonds for the whole EZ. The constantly high 
demand for them is connected with collateralization and foreign bond holders' needs and investors' preferences. Further reduction in the availability of German government bonds caused by the ECB's PSPP purchases and repayments of Germany's public debt clearly caused a higher pressure to increase their prices (decrease of yields) relative to other EZ countries.

Table 3 captures changes in yield by sector, rating quality and changes in other selected indicators. As for sectors, the biggest percentage of the total yield change in 2016-2017 induced by the CSPP goes to consumer staples (79\%), communications, health care and utilities (around 60\%). As for the rating, the effects generally increase with riskiness. The ICE1 index, which tracks emerging markets' corporate bonds denominated in euros, and the ICE2 index, which tracks the euro-denominated below-investment-grade corporate debt, fell significantly by 133 b.p. and 125 b.p. respectively. It is clear from these two indices that the impact of the CSPP announcements spilled over to the segment of CSPP-ineligible corporate bonds.

Table 3: AYTM by sector / rating (in b.p.)

\begin{tabular}{|c|c|c|c|}
\hline Sector & $\begin{array}{c}\text { Total } \\
\text { change }\end{array}$ & $\begin{array}{c}\text { ES } \\
\text { change }\end{array}$ & $\begin{array}{c}\text { ECB } \\
\text { Portfolio } \\
\text { Share (\%) }\end{array}$ \\
\hline $\begin{array}{l}\text { Communica- } \\
\text { tions }\end{array}$ & -65.8 & -40.7 & 9.4 \\
\hline $\begin{array}{l}\text { Consumer } \\
\text { Discretionary }\end{array}$ & -74.1 & -21.4 & 13.8 \\
\hline $\begin{array}{l}\text { Consumer } \\
\text { Staples }\end{array}$ & -58.1 & -45.7 & 7.8 \\
\hline Energy & -88.8 & -53.8 & 6.8 \\
\hline Financials & -74.0 & -35.0 & 10.5 \\
\hline Health Care & -42.5 & -24.8 & 3.4 \\
\hline Industrials & -55.7 & -24.0 & 12.7 \\
\hline Materials & -67.8 & -26.9 & 8.3 \\
\hline Technology & -93.1 & -35.9 & 1.6 \\
\hline Utilities & -67.3 & -38.0 & 25.6 \\
\hline
\end{tabular}

\begin{tabular}{l|c|c}
\hline $\begin{array}{l}\text { Rating } \\
\text { Quality }\end{array}$ & $\begin{array}{c}\text { Total } \\
\text { change }\end{array}$ & $\begin{array}{c}\text { ES } \\
\text { change }\end{array}$ \\
\hline High Grade & -67.4 & -30.3 \\
\hline $\begin{array}{l}\text { Upper Medium } \\
\text { Grade }\end{array}$ & -62.6 & -23.9 \\
\hline $\begin{array}{l}\text { Lower Medium } \\
\text { Grade }\end{array}$ & -80.3 & -49.1 \\
\hline Other / Not rated & -22.3 & -10.2 \\
\hline $\begin{array}{l}\text { Other Indicators } \\
\text { change }\end{array}$ & change \\
\hline ICE1 & -335.0 & -133.0 \\
\hline $\begin{array}{l}\text { ICE2 } \\
\text { CBOE Volatility }\end{array}$ & -14.4 & 8.9 \\
\hline Index (VIX) & -304.0 & -125.0 \\
\hline $\begin{array}{l}\text { EUR-USD Spot } \\
\text { Exchange Rate }\end{array}$ & 843.0 & 92.0 \\
\hline $\begin{array}{l}\text { EURO STOXX 50 } \\
\text { Price EUR }\end{array}$ & 573.0 & -16.0 \\
\hline
\end{tabular}

Source: own calculations 
The volatility index (VIX) surged considerably around the CSPP-related events, which is quite expectable given the unconventional nature of implemented measures and low awareness of markets about the CSPP and its novelty. The EUR-USD rate rose 92 pips and the Euro Stoxx 50 price in EUR exerted no strong movement pattern on average. However, in the long term, in 2016-2017, the Euro Stoxx 50 rose by almost 600 EUR, which is $20 \%$ of its value as of 1 January 2016 . That could be partially caused by investors shifting their portfolios from fixed-income markets to equity markets and it would support the portfolio rebalancing hypothesis.

Figure 2 captures the total movement of the AYTM of CSPP-eligible bonds, with the shaded part directly assignable to ES events and with the dots representing the movement adjusted for OIS changes. As for longer maturities and lower ratings, the ES succeeded in capturing most of the movement. The OIS-adjusted measurement gives us a better idea about the yield change that was caused by the APP expansion rather than the change in expected future monetary policy rate. It is clear that expectations of future monetary policy rates reflect the fact that sooner or later the ECB will have to increase its rates - longer maturities exert low OIS change with respect to overall change.

\section{Figure 2: AYTM change in b.p. (for selected segments)}

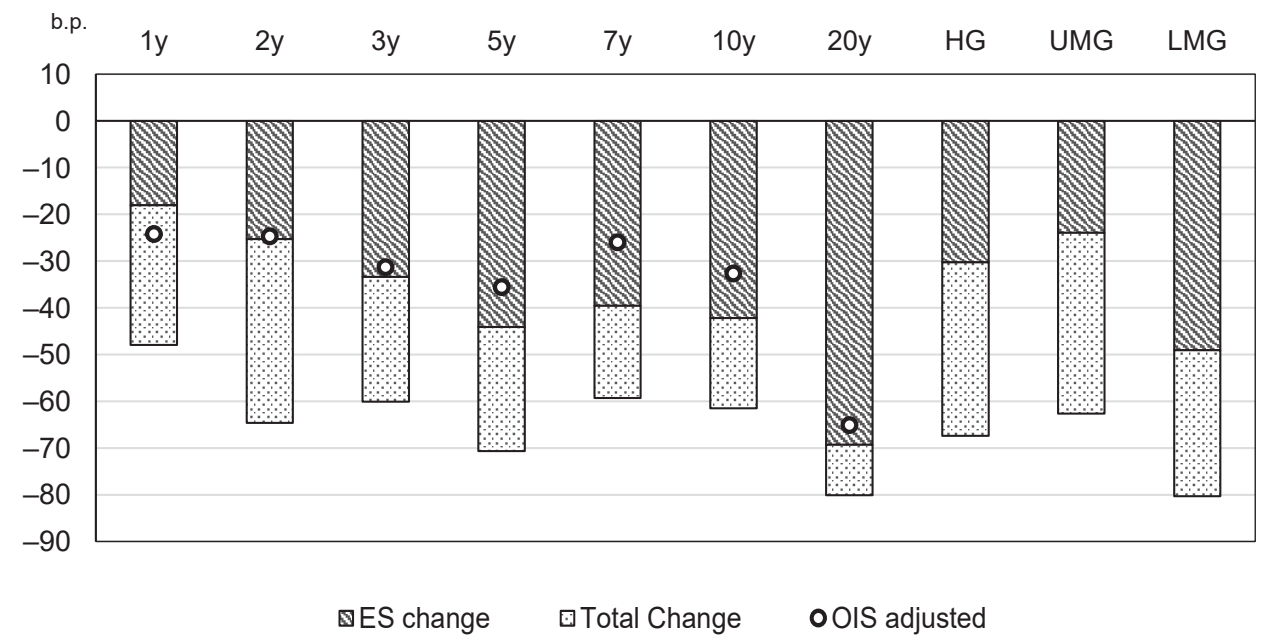

Note: HG stands for high-grade rated bonds, UMG for upper-medium-grade rated bonds and LMG for lower-medium-grade rated bonds; source: own calculations

Source: own calculations 
Several interesting facts are noticeable from Figure 3, which represents the distribution of the yield changes in the 5-year segment in time. First two big drops in the yields are noticeable around the ECB's key CSPP decisions in March 2016 and October 2017, which clearly shows that a message from the ECB was transferred to the markets via a signal transmission channel. Followed by a drop in June and July 2016, when the ECB actually started to buy bonds on the markets, and its real presence stirred bond prices and it could actually happen via the portfolio rebalancing channel. The period between October 2016 and June 2017 was marked by ambiguous signals from the EZ economy, several geopolitical turbulences and even signs of a possible QE tapering. These factors caused pressure on bond yields from both sides and the ECB waited until the situation became more settled.

Figure 3: Monthly purchases in billion EUR and 5-year AYTM change (in b.p.)

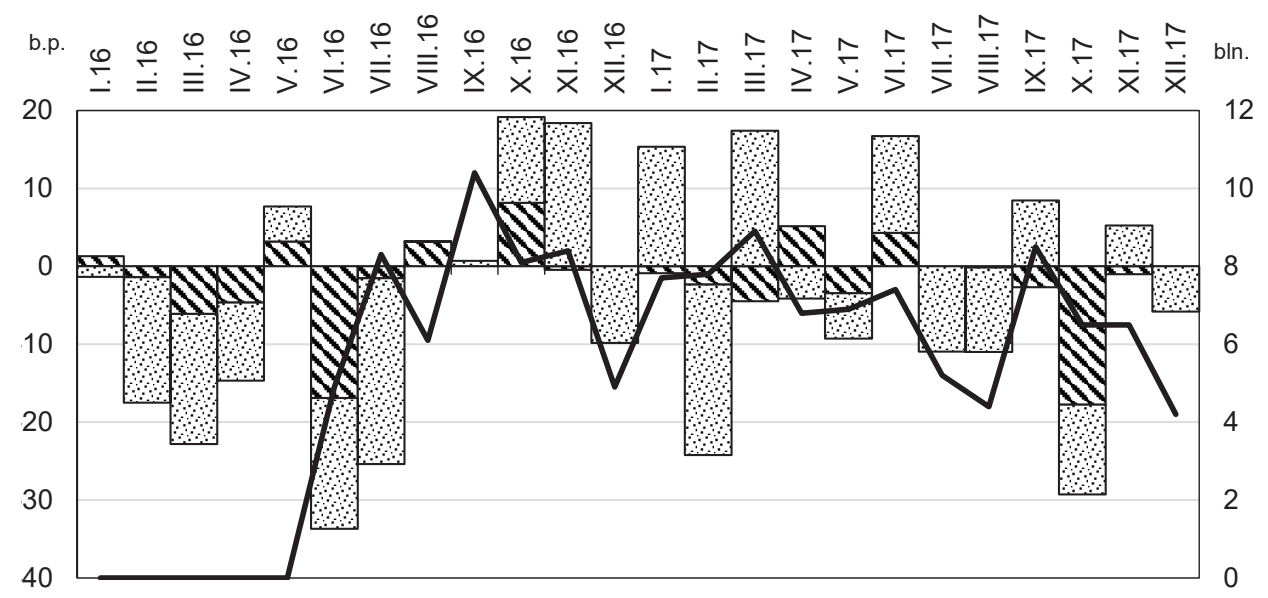

WEvent change Total change -ECB CSPP vol. (right axis)

Source: own calculations

The period between October 2016 and June 2017 was also characterized by a dramatic fall in the expected time to the first hike of ECB rates from almost 50 months in September 2016 to 12 months in April 2017 and remaining low. ${ }^{11}$ Furthermore, in December 2016 the ECB decision was perceived as less dovish than expected, even though the APP

11 Bloomberg questionnaire inquiry. 
extension introduced was longer than expected (but lower in size) and the reinvestments of the principal payments from the maturing securities purchased under the APP were introduced together with the removal of the APP deposit rate floor constraint. Forward guidance did not do the job well this time and the yields were on the rise. As the economic outlook improved, the signal that asset purchases sent regarding the likely date of the first rate hike became increasingly important for anchoring of the medium-to-long-term segment of the curve, as said by Cœure (2018). The strong signal regarding the APP, which was needed in 2016 and which the ECB clearly failed to send, was sent later on in October 2017. However, it is likely that the stock effect of the ECB's CSPP holdings together with a persistent flow of purchases prevented yields from rising even higher during this period.

\section{VAR-IRF Analysis}

In order to discover and quantify a possible relationship among CSPP-incorporating data time series affected by the monetary policy decisions, this analysis uses the vector autoregression model (VAR). This model is frequently used in studies analysing monetary policy - see, e.g., Bernanke and Kuttner (2004), Gagnon et al. (2010) or Christensen and Rudebusch (2012). The VAR is a stochastic process model that can be used to reveal linear interdependencies between time series and to allow bypassing an a priori determination of exogeneity, or endogeneity, of variables. Capabilities of VAR modelling, exploited in this paper, are described and advocated, e.g., in Stock and Watson (2001). In this study, series of maturity, country, sector and company-specific recursive VAR models were constructed together with their impulse-response functions (IRFs) to quantify the strength and the persistence of CSPP-related monetary policy shocks. The VARs were also supplemented by Granger-causality tests disclosing dynamics in concerned time series. ${ }^{12}$ Constructed VAR models can be perceived as semi-structural under certain conditions as advocated in Watson (1994). The recursive VARs constructed in this section construct the error term in each of $\boldsymbol{n}$ regression equations to be uncorrelated with the error term in the preceding equation, unlike the reduced form of the VAR, using a Cholesky factorization of the reduced-form VAR covariance matrix; see Lütkepohl (1991) or Hamilton (1994) for details. Identifying assumptions taken in the causal interpretation of the equation correlations make these VARs semi-structural by the proper ordering of the variables in the model equations. For details on identifying assumptions

12 Granger-causality tests confirmed a priori considered relations among time series used in this study. 
in VAR models, see Sims (1986) or Watson (1994). In this case, the variable ordering is straightforward with a given set of time series. It is apparent which comes first and what is the causal relationship among them, which allows us to impose these ordering restrictions. ${ }^{13}$ This paper assumes a causal relationship from the APP to asset prices and consequently yields in the constructed models and not vice versa.

Formally written, the $p$-lag vector autoregressive $\operatorname{VAR}(p)$ model has the form:

$$
y_{t}=\mathrm{c}+\Pi_{t} y_{t-1}+\Pi_{2} y_{t-2}+\cdots+\Pi_{p} y_{t-p}+\varepsilon_{t},
$$

where $\boldsymbol{y}_{\boldsymbol{t}}$ is the vector of time-series variables, $\boldsymbol{\Pi}_{\boldsymbol{i}}$ are the coefficient matrices and $\boldsymbol{\varepsilon}_{\boldsymbol{t}}$ is the serially uncorrelated or independent vector process. ${ }^{14}$ Each single equation of this $\operatorname{VAR}(p)$ has the same regressors, which are the lagged values of the $\boldsymbol{y}_{\boldsymbol{t}}$ elements. In order to construct IRFs, the $\operatorname{VAR}(p)$ must have the triangular structural matrix form:

$$
\mathrm{B} y_{t}=\mathrm{c}+\Gamma_{1} y_{t-1}+\Gamma_{2} y_{t-2}+\cdots+\Gamma_{p} y_{t-p}+\eta_{t},
$$

where $\mathbf{B}$ is a lower triangular matrix and $\boldsymbol{\eta}_{\boldsymbol{t}}$ is an error vector term. This form of the $\operatorname{VAR}(p)$ is achieved by proper ordering of the variables in the model using so-called "recursive causal ordering", where imposed ordering restrictions are made in a way that the contemporaneous value of each variable placed in the model affects only the contemporaneous values of other variables added later but not the values of variables added before it. Consecutive residual orthogonalization gives us the desired orthogonal impulse-response functions (IRFs), which incorporate the graphic representation of the impact of one SD shock to one variable (in this case the monetary policy decision variable) on another (the bond yield variable).

The data set for the VAR analysis in this section consists of a variety of time series with a daily frequency: the time series presented in Section 3 (average yields to maturity [AYTM] of CSPP-eligible bonds sorted by maturity / country / rating / sector, etc., modified time series representing key ECB monetary policy actions, OIS rates by maturity, sovereign benchmark bond yields by maturity) extended for a time series representing the ECB's CSPP portfolio weekly holdings sorted by various criteria ${ }^{15}$ and finally a time series reflecting bond issues of ten selected model companies. These time series give us a ground for constructing dozens of VARs using different criteria: maturity, country, sector or rating of underlying bonds therefore only the most important representative results are presented below.

13 First is clearly the monetary policy decision and the market reaction follows afterwards.

$14 \varepsilon_{t}$ must have a covariance matrix that is time-invariant.

15 Based on available ISINs of ECB weekly holdings. 
All the macroeconomic and political events stated in Section 3 (Brexit for example) are omitted from the time series in order not to affect the outcome of the VAR analysis. Each constructed VAR ${ }^{16}$ consists of only several selected time series, e.g., the 3-year VAR model consists of five time series. VAR(3): 3-year corporate AYTM, 3-year government benchmark bond AYTM, 3-year OIS rate, ECB monetary policy decisions and ECB bond holding of given 3-year maturity. Other constructed VARs contain the same time series corresponding to their maturity. Lags for endogenous variables were selected according to information criteria and, e.g., the lag length for the 3-year VAR is 3. The data span for all the VARs is from 1 January 2016 to 31 December 2017.

The IRFs shown below depict the responses of the selected current and future value of a variable to a Cholesky one-SD innovation (increase of one SD in one of the VAR errors) $\pm \boldsymbol{m}$ SE, under the assumption that this error will return to zero in the following periods and that the other errors are zero. The IRF and the accumulated response function of 3-year average bond yield are depicted in Figure 4 to illustrate the yield response of a given maturity to one-SD innovation in the variable capturing the ECB's CSPP decisions. The IRFs for the other treasury maturities are similar in shape as those in the 3-year sample and differ only in magnitude; therefore, only the overall response is enclosed below in Figure 5. The response of the AYTM of the corporate sector bonds with 3-year maturity to one-SD innovation in the ECB's CSPP decision calendar time series is shown in Figure 4.

\section{Figure 4: IRFs for 3-year AYTM}
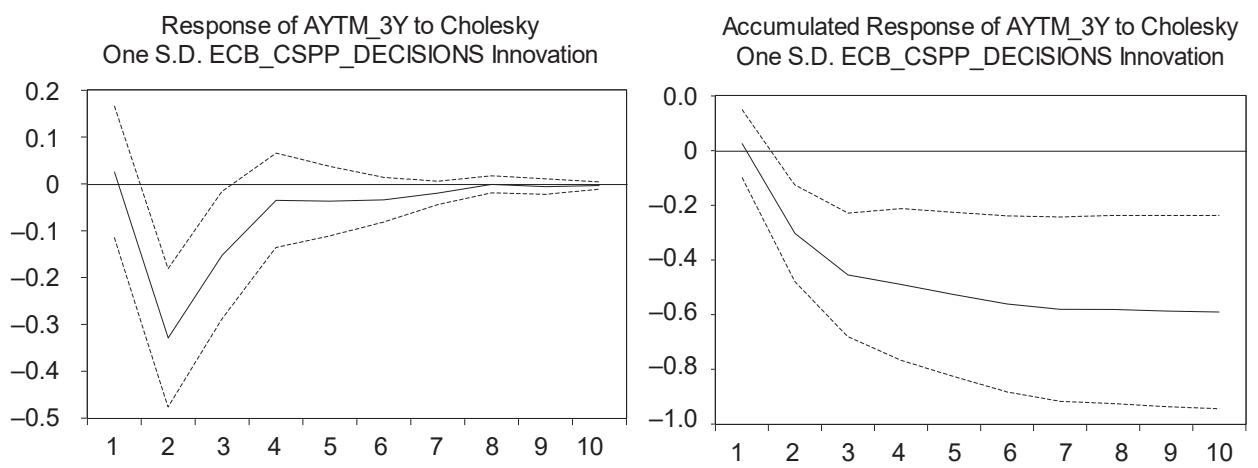

Source: model output results (EViews)

16 All VAR components were tested for stability and stationarity using standard procedures. 
In this model case, the cumulated response rescaled from one SD shock is around -20 b.p. in one week after a monetary policy shock similar in size to the ECB's March 2016 decision. The response is very quick and quickly fading in approx. 4 days, when most of the response is present - exactly what one would assume about the reaction of asset yields to monetary policy announcements. All other time series representing changes in AYTM across different maturities, countries of issuance, ratings and sectors follow the same pattern in the IRFs; therefore, only maximums of the cumulative response functions with a reaction time of seven days are depicted and argued in the following figures and comments. The first column in Figure 5 represents "raw" change of an average yields of a given maturity; the second one represents the same yields adjusted for OIS movements - here it should again provide a better idea about the reaction induced by the decision about the CSPP rather than changes in the expected path of future interest rates. It is evident from Figure 5 that the reaction of OIS-adjusted yields is lower than that of the unadjusted ones and it is likely that it is caused by the fact that all monetary policy measures (rate changes, APP programme, forward guidance, etc.) act together. The strength of the reaction is roughly around -20 b.p. unadjusted an around -10 b.p. adjusted in the most important maturities of 3-10 years.

\section{Figure 5: AYTM reaction from IRFs by maturity (in b.p.)}

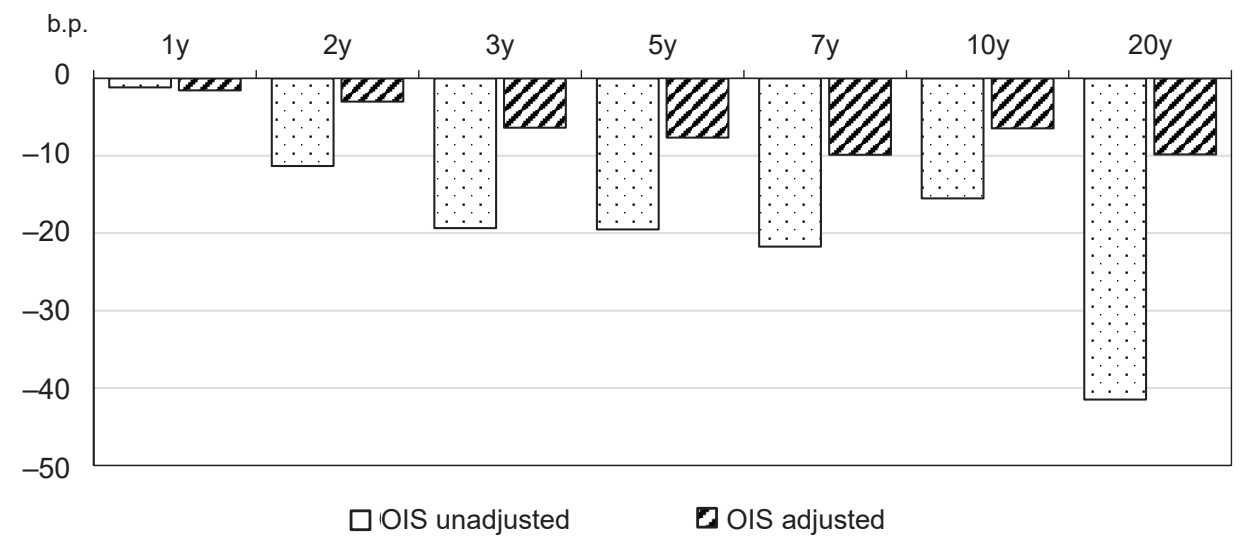

Source: own calculations

The reaction of the AYTM divided by the country of issue corresponds to the reaction in Figure 5 with respect to its country composition - the reaction is stronger for Italy ( -36 b.p. on 5 -year maturity), Spain ( -22 b.p.) and France ( -40 b.p.) and ambiguous 
for Germany ( -2 b.p.). Unlike in Section 3, the analysed reaction from IRFs is stronger for days around the ECB's CSPP announcements but cannot capture the whole reaction due to a different structure of the time series, which represents only the key events well defined as for length and size of the CSPP purchases.

For the quantification of effects of the CSPP programme on the micro level, ten model companies from the main EZ countries with multiple bond issuances were chosen: Abertis Infraestructuras [SP], BASF [GE], Daimler [GE], Danone [FR], Eni [IT], Orange [FR], Sanofi [FR], SAP [GE], Telecom Italia [IT] and Telefonica Emisiones [SP]. Ten synthetic portfolios of the above companies were analysed for the daily yield changes induced by the main CSPP decisions and for the daily yield changes caused by inclusion of particular bond issues in the ECB portfolio. The first approach is the same as in the above IRFs for different maturities; the second one uses the weekly announced ECB ISIN-based holdings and allows us to analyse the reaction of underlying bond prices to real ECB presence on the markets rather than just announcements. ${ }^{17}$ The announcement reactions are represented by the first column for each company in Figure 6 ("decision" column). The reaction of the yields of synthetic portfolios to additional bond issues bought by the ECB is represented by the second column ("count").

Figure 6: AYTM reaction from IRFs (in b.p.)

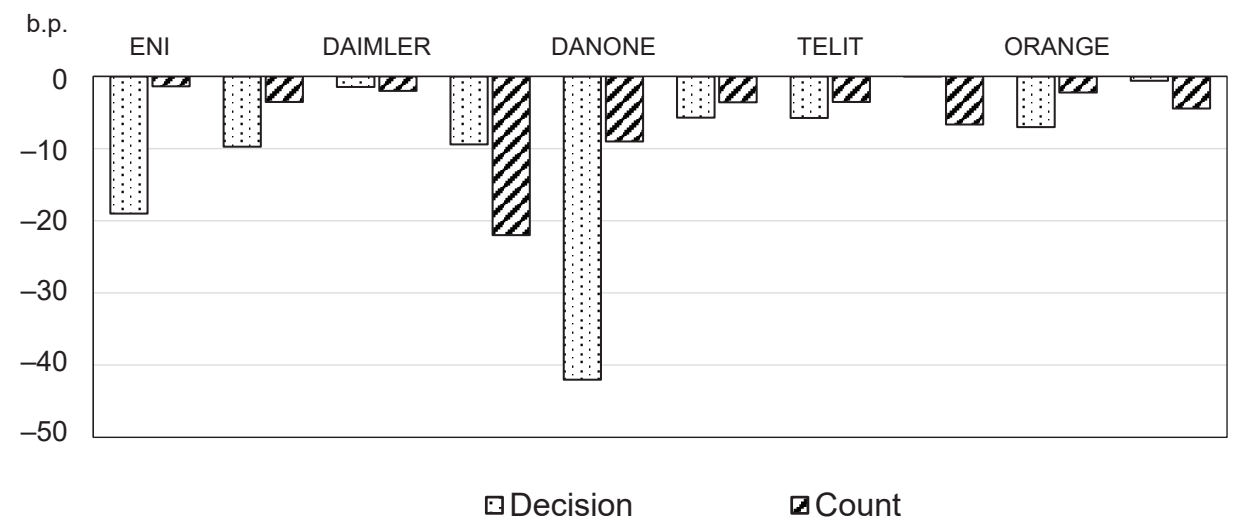

Source: own calculations

17 This type of analysis is, however, quite shallow due to lack of precise data - the ECB publishes only weekly held ISINs with no additional information about the amount held. Therefore, only a binomial time series for each ISIN expressing presence in the ECB portfolio is used. 
A significant yield reaction to the ECB's CSPP announcements is present for the synthetic portfolios of Danone (over -40 b.p.) and Eni ( -20 b.p.) and fairly limited for Daimler or SAP. The reaction to real ECB purchases of issues on the market is strong for Sanofi ( -20 b.p. per issue bought), Danone ( -10 b.p.) and BASF ( -7 b.p.). The following section covers a breakdown of the particular characteristics of the corporate financing and changes in this area caused by the introduction and implementation of the CSPP.

\section{Impact of CSPP on Corporate Financing}

Important characteristics of the corporate bond market that may have been affected by the ECB's monetary policy are several types of premiums claimed by private investors to hold corporate bonds - term premium, credit risk premium and liquidity premium. Figures 7 and 8 depict the premiums in 2016-2017 for both CSPP-eligible and CSPPineligible corporate bonds issued in EUR. They are proxied from the average slope of the yield curve for the term premium ${ }^{18}$, from the yield spread between bonds with higher and lower rating ${ }^{19}$ for the credit premium and, for the liquidity premium, from a composite measure of liquidity composed from market price bid-ask spread and yield spread between issues with different issuance sizes. The composite measure of liquidity composed from market price bid-ask spread is advocated in Edwards et al. (2007).

\section{Figure 7: CSPP-eligible premiums (\%)}

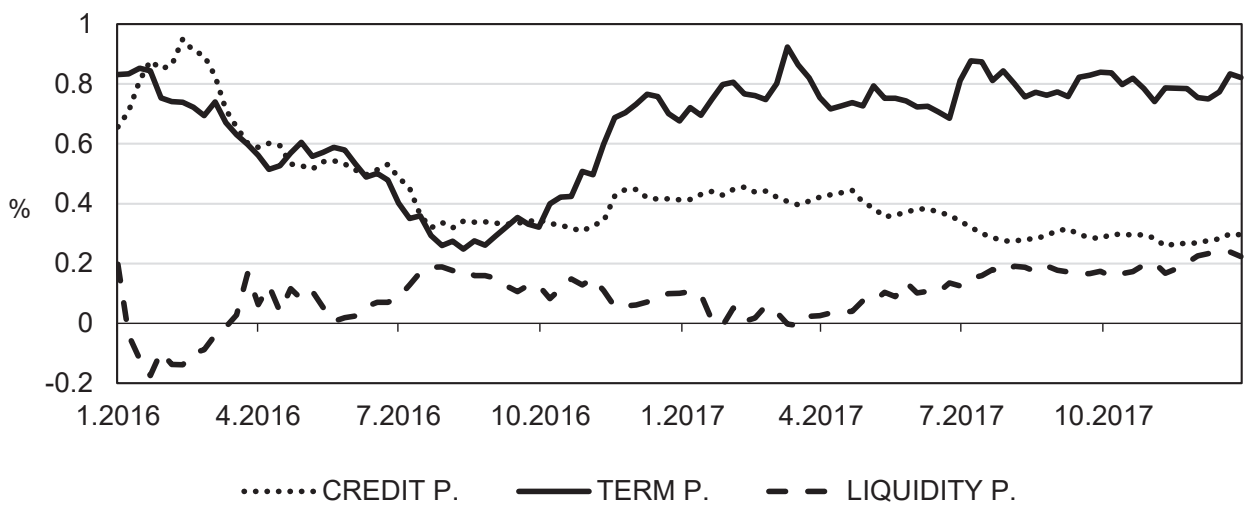

Source: own calculations

18 Calculated as 7-year yield minus 2-year yield of A-/A/A+ bonds for Figure 7 and from the same maturities, but lower ratings (BB-/.../BBB + ), for Figure 8 .

19 For the CSPP- eligible pool from high grade vs. lower medium grade spread and for the CSPPineligible pool as BBB-/.../AA vs. $\mathrm{DD}+/ \ldots / \mathrm{BB}+$. 
It is clear from Figure 7 that the CSPP announcement by the ECB at the beginning of 2016 had a considerable effect on the credit and term premium of CSPP-eligible bonds, where the credit premium for CSPP-eligible bonds fell from almost $1 \%$ to approx. $0.3 \%$ and the term premium from $0.8 \%$ to $0.3 \%$. The term premium, however, did not stay on this level and returned to a level close to $0.8 \%$. The liquidity premium did not show any significant reaction to the CSPP announcements and stayed in a range from 0 to $0.2 \%$ most of the time.

Figure 8 represents all other corporate non-financial bonds denominated in EUR and it does not show any similarities in changes of premiums with the CSPP-eligible pool. The term and credit premiums are almost unchanged throughout the period; the liquidity premium is highly volatile in the first third of 2016 but then around April 2017 it falls from $2.5 \%$ to $1 \%$ and stays resistant after that. It is not likely that the ECB managed to maintain the term premium on low levels, after its initial successful lowering, as ECB officials would like to see, at least not since the ECB's September 2016 decision, which failed to deliver a strong message, though monetary policy changes were expected by markets.

\section{Figure 8: CSPP ineligible premiums (\%)}

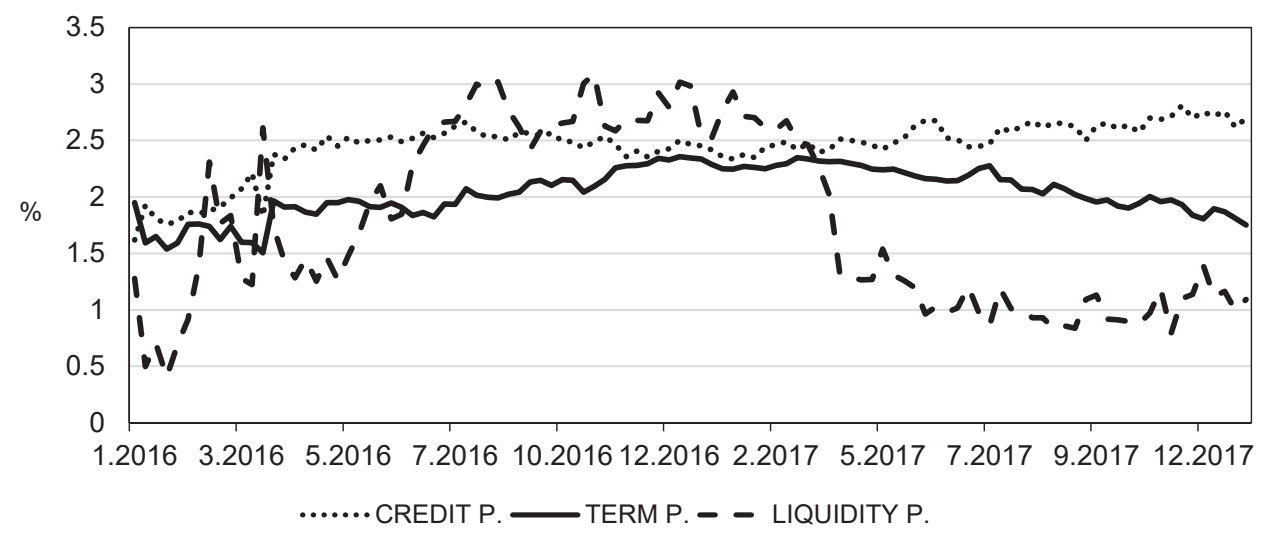

Source: own calculations

The development on the markets for corporate financing was quite dynamic in both conventional bank loan-financing and more non-traditional bond issuing. Availability of bank loans to the corporate sector, especially SMEs, is embodied in lowering of average loan interest rates. Figure 9 shows a constant decrease in the average bank loan interest 
costs, represented by the costs of borrowing to corporations in the euro area ${ }^{20}$, from $2.1 \%$ to $1.7 \%$, and also the trend of total volume reduction around $15 \%$ in $2016-2017$.

\section{Figure 9: Non-financial corporate bank lending in EZ [\%]}

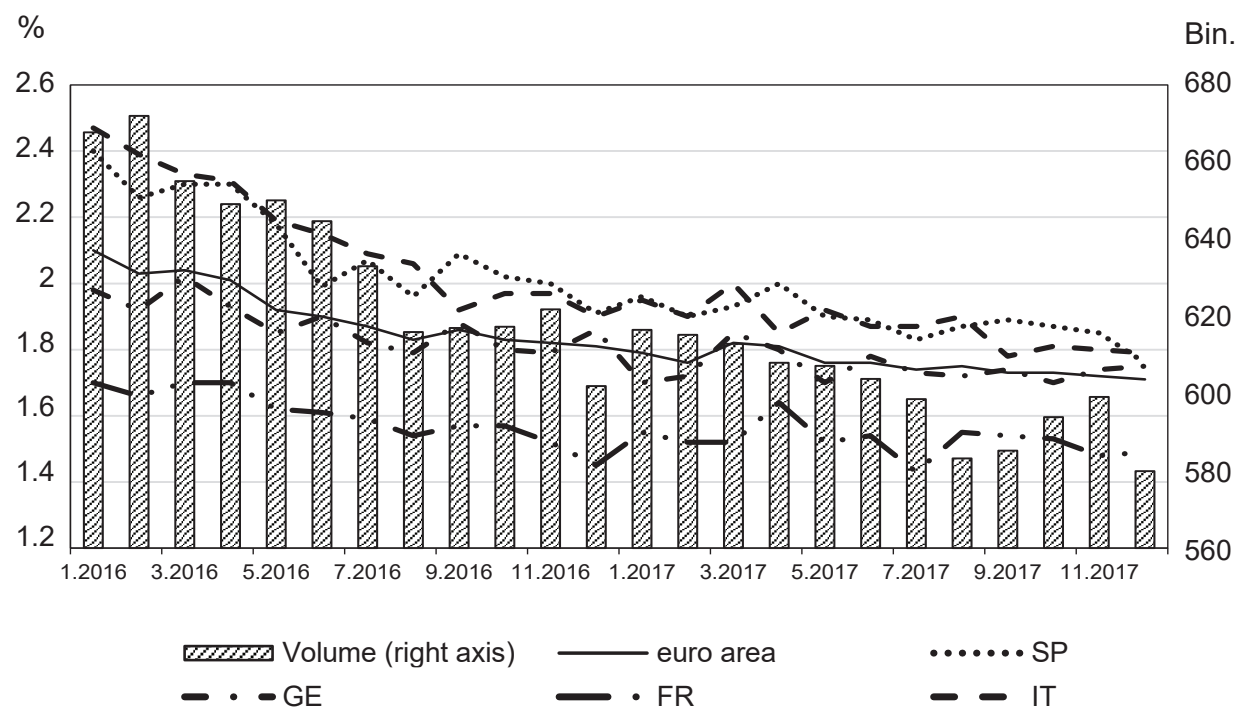

Source: $E C B / M F I$

In the fixed income segment, the 5-year bond yield fell on average by 70 b.p. and by almost 40 b.p. more than national government benchmark bonds (measured for Germany, France, Italy and Spain), which represents a significant decrease of capital acquisition costs by bond issuance. A stable growth of the cumulative volume of bonds issued in both investment-grade and high-yield segments is shown in Figure 10.

It is clearly identifiable from the markets for non-financial corporate bank loans and bonds that the ECB's CSPP programme has had a significant effect on the financing of non-financial corporate sector, especially on the segment of CSPP-eligible issuers. The effects were transferred to the ineligible universe to some extent as well. The trend is clear as for the selected companies from Section 4, e.g., BASF increased its emission of Eurobonds in 2016 and even more in 2017 and simultaneously lowered its obligations to banks around 20\% between the end of 2015 and 2017. ${ }^{21}$ Daimler used bond issuance

20 Reported by the ECB.

21 Data from BASF annual reports from 2014-2017. 
to a greater extent as well; this time, however, mainly on the US soil rather than in Europe. ${ }^{22}$

Figure 10: Cumulative non-financial corporate bond issuance in EUR

BIn.

BIn.

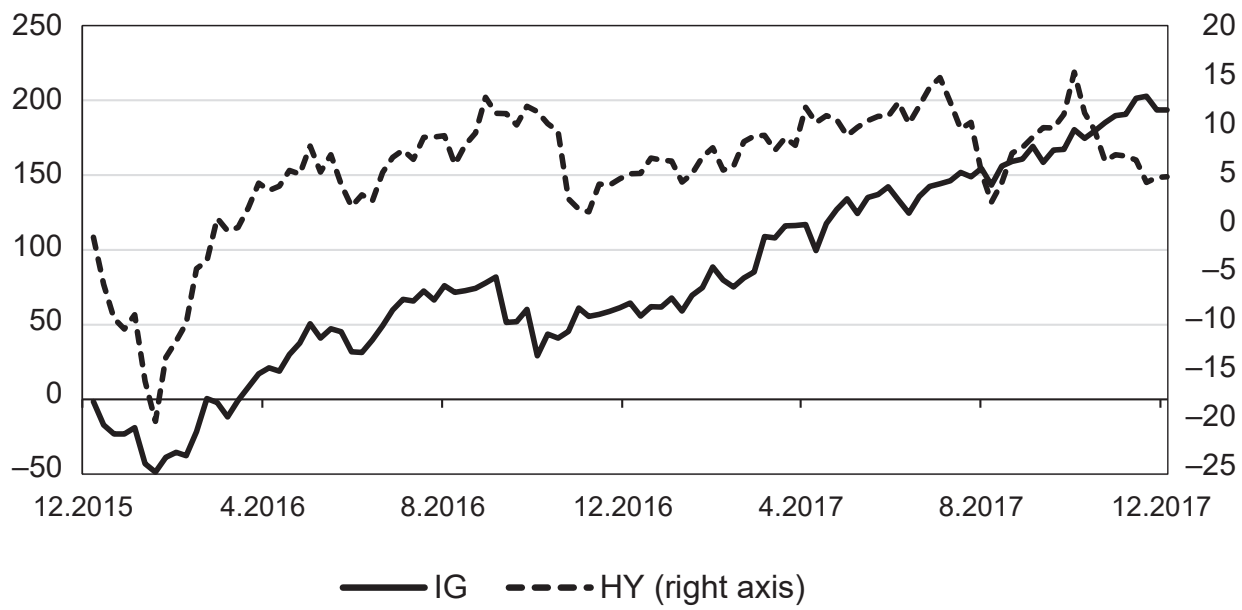

Source: Bloomberg-Barclays

\section{Conclusions}

Together with the PSPP, the CSPP is an important monetary policy tool especially in its segment of corporate non-financial bonds. The CSPP has had non-negligible effects on yields of targeted assets, especially on CSPP-eligible bonds with a transmission to the CSPP-ineligible universe. Term and credit premiums were unambiguously affected in the eligible universe. In the ineligible universe, it was rather liquidity premium that was affected second-hand. The event study revealed the strength of CSPP effects on corporate yields on a cross-country range of maturities, ratings and segments. What is important is the adjustment for movements of the expected path of the ECB rates represented by OIS yield curve changes and the adjustment with respect to particular quasi risk-free yields represented by the yield curve of national sovereign bonds. The event study also showed an interesting distribution of the yield change across the given time span and, unsurprisingly, identified the strongest effects

22 Data from Daimler annual reports from 2015-2017. 
around the ECB's key CSPP decisions. The VAR-IRF analysis showed the responses and cumulative responses of yields across maturities and countries of the eurozone to imposed monetary policy shocks of the same size as the one from the March 2016 decision. The IRFs also revealed the reaction of the bond issues of ten selected companies on the ECB's monetary policy announcements of the CSPP and real ECB purchases of these issues. The CSPP affected the real markets of corporate financing and it is possible to identify several possible changes that may be traceable to the CSPP.

Of course, the prices of corporate bonds will fall eventually in the environment of strong economic recovery and better corporate economic perspectives - the improving outlook of the present day will naturally drive bond yields higher as expectations of the future ECB rate path level will rise. Then the question is what the ECB will do with its holdings of corporate and mainly sovereign bonds. There are already hints that the ECB will walk the path of swelled balance sheet as is the case of the Federal Reserve and change the policy tools towards setting the desirable yields on the benchmark yield curve, as done by the Bank of Japan. One way or another, the story of quantitative easing in the eurozone is not yet over.

\section{References}

Altavilla, C., Carboni, G., Motto, R. (2015). Asset Purchase Programmes and Financial Markets: Lessons from the Euro Area. European Central Bank. Working Paper No. 1864.

Andrés, J., Lopez-Salido, D., Nelson, E. (2004). Tobin's Imperfect Asset Substitution in Optimizing General Equilibrium. FED. St. Louis Working Paper No. 003A.

Bates, M., Watts, G. (1988). Nonlinear Regression Analysis and its Applications. New York: John Wiley \& Sons. ISBN 9780471816430.

Bernanke, B., Kuttner, K. (2004). What Explains the Stock Market's Reaction to Federal Reserve Policy? FED. New York Staff Report No. 174, https://doi.org/10.3386/w10402

Briciu, L., Lisi, G. (2015). An Event-study Analysis of ECB Balance Sheet Policies since October 2008. European Economy Economic Briefs No. 001.

Christensen, J., Rudebusch, G. (2012). The Response of Interest Rates to US and UK Quantitative Easing. The Economic Journal, 122(564), F385-F414, https://doi.org/10.1111/j.1468-0297.2012.02554.x

Clouse, J., Henderson, D., Orphanides, A. et al. (2003). Monetary Policy when the Nominal Short-Term Interest Rate is Zero. Topics in Macroeconomics, 3(1), https://doi. org/10.2202/1534-5998.1088

Cœuré, B. (2018). The Persistence and Signalling Power of Central Bank Asset Purchase Programmes. US Monetary Policy Forum, NY, 23 February.

D'Amico, S., King, T. (2010). Flow and Stock Effects of Large-Scale Treasury Purchases. FED. Washington, D.C. Finance and Economics Discussion Series, https://doi.org/10.2139/ ssrn. 1702314 
ECB (2017). The Transmission of the ECB's Recent Non-standard Monetary Policy Measures. Economic Bulletin, 7.

Edwards, A. K., Harrusm A. E., Piwowar, M. S. (2007). Corporate Bond Market Transaction Costs and Transparency. The Journal of Finance, 62(3), 1421-1451, https://doi. org/10.1111/j.1540-6261.2007.01240.x

Eggertsson, G., Woodford, M. (2003). The Zero Bound on Interest Rates and Optimal Monetary Policy. Brookings Papers on Economic Activity No. 1.

Gagnon, J., Raskin, M., Remache, J. et al. (2011). The Financial Market Effects of the Federal Reserve's Large-Scale Asset Purchases. International Journal of Central Banking, 7(1), 3-43.

Gagnon, J., Raskin, M., Remache, J. et al. (2010). Large-Scale Asset Purchases by the Federal Reserve: Did They Work? FED. New York Staff Report No. 441, https://doi.org/10.2139/ ssrn.1576596

Hamilton, J. (1994). Time Series Analysis. Princeton, New Jersey, USA: Princeton University Press. ISBN 0-691-04289-6.

Hamilton, J., Wu, J. (2011). The Effectiveness of Alternative Monetary Policy Tools in a Zero Lower Bound Environment. National Bureau of Economic Research. Working Paper No. 16956, https://doi.org/10.3386/w16956

Hausken, K., Ncube, M. (2013). Quantitative Easing and Its Impact in the US, Japan, the UK and Europe. Springer. ISBN 978-1-4614-9646-5.

Joyce, M . et al. (2011). The Financial Market Impact of Quantitative Easing in the United Kingdom. International Journal of Central Banking. Bank of England.

Joyce, M., Miles, D., Scott, A. et al. (2012). Quantitative Easing and unconventional Monetary Policy - An Introduction. The Economic Journal, 122(564), F271-F288, https://doi. org/10.1111/j.1468-0297.2012.02551.x

Krishnamurthy, A., Vissing-Jorgensen, A. (2011). The Effects of Quantitative Easing on Interest Rates: Channels and Implications for Policy. National Bureau of Economic Research. Cambridge, MA Working Paper No. 17555, https://doi.org/10.3386/w17555

Lütkepohl, H. (1991). Introduction to Multiple Time Series Analysis. Springer. ISBN 0-387-53194-7.

Sims, CH. (1986). Are Forecasting Models Usable for Policy Analysis? Quarterly Review, 10(1), 2-16. Winter issue .

Stock, H., Watson, M. (2001). Vector Autoregressions. The Journal of Economic Perspectives, 15(4), 101-115, https://doi.org/10.1257/jep.15.4.101

Vayanos, D., Vila, J. (2009). A Preferred Habitat Model of the Term Structure of Interest Rates. National Bureau of Economic Research. Working Paper No. 15487, https://doi.org/10.3386/w15487

Watson, M. (1994). Vector Autoregressions and Cointegration. Northwest University and Federal Reserve Bank of Chicago. Handbook of Econometrics, Vol. IV. 